\title{
O Que disse Derrida quando $o$ acontecimento chegou
}

\author{
FELIPE AMANCIO *
}

\begin{abstract}
RESUMO Em torno da questão do acontecimento, daquilo que chega como inesperado e imprevisível, o presente trabalho tem por objetivo tomar os últimos escritos de Jacques Derrida sobre o tema em articulação a um acontecimento específico: o 11 de setembro. Para tanto, toma-se tanto os escritos que antecedem ao acontecido, quanto os posteriores, com o objetivo de remontar o entendimento do autor sobre a tema. Sobre este que foi veiculado com um grande acontecimento histórico, Derrida nos apresenta uma posição que não se entrega à constrição de uma comoção condicionada, buscando antes, entender as origens do ocorrido a partir do cenário que se desdobrou desde a Guerra Fria, os mútuos ataques e as tentativas de defesa, ou de sua própria corrosão, pela noção de autoimune. Veremos também como a questão do acontecimento articula questões caras ao mundo contemporâneo, como o terrorismo, a globalização, a hospitalidade e o cosmopolitismo.
\end{abstract}

PALAVRAS-CHAVE acontecimento; autoimune; Derrida.

NUMA EDIçÃo ESPECIAL da revista Communications, Edgar Morin inicia seu texto “O retorno do acontecimento" (Le retour de l'événement) com a seguinte máxima: "Não há ciência do singular, não há ciência do acontecimento, este é um dos pontos mais firmes de uma vulgata teórica ainda dominante. (tradução nossa) ${ }^{1 ”}$. O texto em questão, não trata especificamente de filosofia, antes busca traçar um panorama sobre como a questão do acontecimento atravessa diferentes campos do saber. Identificado

* Mestrando PUC-Rio / Bolsista CAPES

1 No original: “Il n’y a pas de sience du singulier il n'y a pas de sience de l'evenement, c'est là um des points les plus assurés d'une vulgate théorique encore dominante.” Cf. Morin Edgar. Le retour de l'événement. p.6 
ao singular e à contingência do acidental, o acontecimento tem sido escondido, evitado tanto nas ciências da natureza, quanto nas humanidades, por irromper a lógica de um sistema de saber estabelecido, muito pautado nos paradigmas da física moderna. Em contrapartida, Morin observa que atualmente, a própria física tem se afastado desse modelo, que outras ciências ainda perseguem, e se aproximado do problema para entender a própria formação do universo como decorrente de um grande acontecimento originário, explosivo, que deu origem a tudo o que conhecemos ${ }^{2}$.

Retoma-se então o conceito de cosmos para pensar não só o universo, mas este como decorrente de um acontecimento inaugural que determinou o tempo e o espaço como condições necessárias para a observação das leis que viemos identificar. Posto isso, é curioso como o estado anterior a tal acontecimento nos é vedado, assim como a ideia de um acontecimento em estado puro, contudo, a regularidade que se segue também não está isenta de acidentes com explosões estrelares e colisões de galáxias. Disso o autor conjectura que a natureza singular e evolutiva do mundo é inseparável de uma dimensão acidental da ordem do acontecimento; em seu entender, o cosmos não se torna aquilo que ele deveria ser, à maneira hegeliana, pelo desenvolvimento autogenitor de um princípio de lógica dialética, mas evolui do modo que é, como uma sucessão de acontecimentos, transformações que se afastam do original por reencontros e rupturas ${ }^{3}$.

Após essa introdução de dimensões astronômicas, o autor reduz sua escala de análise para a vida humana, entendendo-a como decorrente de um suposto princípio de heterogeneização do próprio cosmos; em última instância, uma manifestação fruto do acaso, um acidente-acontecimento que veio gerar um sistema-estrutura. Tal duplicidade entre o acidental-ilógico e o regular-estruturado - ou seja, entre o acontecimento e o sistema - é uma dificuldade dialética que se impõe à história e à sociologia que buscam identificar processos auto-gerativos (auto-génératifs) e hetero-generativos (hétéro-génératifs) no curso da história; pois, postular a existência de um processo autogenerativo é supor que os sistemas sociais se desenvolvem autonomamente, não somente a partir dos mecanismos de “crescimento", mas também pelos antagonismos internos que dão início a catástrofes (conflitos sociais, lutas de classes, crises) mais ou 
menos controladas ${ }^{4}$. Isso leva a pensar os sistemas sociais complexos como geradores de acontecimentos, desenvolvendo-se entre a regularidade e o imprevisível.

Contudo, não se busca estender-se aqui na discussão entre história e sociologia, ou mesmo entre as teorias contra ou a favor do acontecimento. Antes, toma-se esse quadro panorâmico, que revela a extensão de limites desconhecidos com a qual se pode pensar o acontecimento, para introduzir como este é entendido por Jacques Derrida. Busca-se então apresentar os apontamentos desse filósofo sobre a questão e, o que disse, quando o acontecimento chegou.

Durante o seminário: Dire l'événement, est-ce possible? que aconteceu em abril de 1997 no Centro Canadense de Arquitetura, Derrida é convidado a discorrer algumas palavras sobre o tema em questão. Logo de início, nos lembra que um acontecimento supõe a surpresa, ser imprevisível - o que revela certa conformidade à maneira com a qual Morin o caracterizou anos antes, e também, a ocorrência de uma acepção, até certo ponto consensual do termo, pelo menos nos círculos intelectuais. Contudo, embora seja uma palavra, ou mesmo um conceito de ampla circulação, para além do que caracteriza o acontecimento, Derrida nos convida a pensar os termos de sua possibilidade, não a partir de uma escala macro, das galáxias ou das sociedades complexas, mas no contexto das relações humanas.

Ao concordar em fazer sua exposição, Derrida diz "sim” à questão homônima ao seminário, mas não no sentido de confirmar a possibilidade de dar conta do acontecimento pela linguagem, "sim" no sentido mais básico e anterior, da aquiescência de ter recebido a questão, antes mesmo de proferir consentimento ou recusa. Em decorrência disso, abordando a primeira palavra do título do seminário, Derrida identifica duas modalidades de "dizer", a saber: o dizer informativo sobre algo e o dizer que faz dizendo - que, em termos das teorias dos "atos de fala” (speech acts), correspondem ao dizer constatativo e o dizer performativo ${ }^{5}$. No entanto, não buscando ater-se profundamente nessa distinção, a utiliza a título de explicação para expor o problema da fala informativa, sempre muito atrasada e genérica em relação à singularidade do acontecimento que já se passou. A performatividade do pretenso dizer e transmitir

4 Idem, ibidem, p.13.

5 DERRIDA, 2012, p.236. 
das mídias, também é apontada, pois acabam por forjar seus próprios acontecimentos, como bem resume: "Um fazer o acontecimento se substitui clandestinamente por um dizer o acontecimento" 6 .

No que se segue, Derrida alerta que, cada vez que se ultrapassa a dimensão do dizer sobre, engajamo-nos numa noite, que não é ignorância, mas é da ordem do não-saber. Uma experiência que para o autor é possível de ser encontrada nos acontecimentos cujas possibilidades se anunciam como impossíveis. No entanto, os exemplos de acontecimentos elencados não são nem um pouco grandiosos, se dão nas relações interpessoais, de modo que podemos perceber, o que nessas relações há de extraordinário, pelo menos enquanto possibilidade do impossível.

O primeiro exemplo tomado é o dom, e Derrida aponta condições muito restritas com as quais um acontecimento de dom pode ser pensado:

É preciso mesmo de uma certa maneira que o outro não saiba que eu dê a ele para que ele possa receber, porque desde que ele saiba, ele está no círculo do agradecimento e da gratidão, ele anula o dom. Do mesmo modo é necessário no limite que eu mesmo não saiba que eu dou. Se eu dou, eu me digo "eis eu dou, eu oferto um presente" [...] Se eu me apresento como doador, eu me felicito já a mim mesmo, eu me agradeço, eu me gratifico a mim mesmo do dom e, por conseguinte, a simples consciência do dom anula o dom. [...] É preciso que o dom não apareça como tal para que ele tenha lugar. Mas nunca se saberá se ele tem lugar. Nunca ninguém poderia dizer, com um critério de conhecimento satisfatório, “tal dom teve lugar”, ou então “eu dei”, “eu recebi”. [...] O acontecimento do dom não deve poder ser dito; desde que se o diz, se o destrói. Dito de outro modo, a medida da possibilidade do acontecimento é dada por sua impossibilidade (DERRIDA, 2012, p.239).

Em moldes muito parecidos são apontadas condições para que certos casos sejam entendidos como verdadeiros acontecimentos, como o perdão, que deve ser do imperdoável, a invenção daquilo que não se sabe poder inventar, e a hospitalidade inesperada, além de toda capacidade de receber. Derrida chama atenção que mesmo aquele faz ou fez o impossível não está em condições de anunciar que algo da ordem

6 Idem, ibidem, p. 237. 
do acontecimento ocorreu, sendo tal fala um absurdo, uma obscenidade ${ }^{7}$. Observemos melhor pelo que o autor diz a respeito do caso da invenção:

\begin{abstract}
Esse enunciado pode parecer um jogo, uma contradição retórica. De fato, sua necessidade, eu a considero irredutível. Se há invenção - talvez nunca haja invenção, do mesmo modo que nunca há dom ou perdão - se há invenção, ela não é possível senão à condição de ser impossível, essa experiência do impossível condiciona a acontecimentalidade do acontecimento. O que chega, como acontecimento, não deve chegar senão ali onde é impossível. Se era possível, se era previsível, é que aquilo não chega ${ }^{8}$.
\end{abstract}

A insistência que Derrida deposita na questão do impossível - possível à condição de ser impossível - condição sem a qual não há acontecimento de fato, é notória e talvez incomoda. De modo que se pode perguntar, se em termos tão restritos, o acontecimento realmente acontece, ou se alguém já o experenciou. Tal formula, como comenta François Raffoul, é tomada de empréstimo do que Heidegger pensou a respeito da morte, esta como a possibilidade da impossibilidade da existência em geral, a possibilidade final e mais própria da vida ${ }^{9}$. Para Derrida, a morte é consequência do acontecimento por excelência.

Buscando problematizar o próprio no impróprio, o possível no impossível, Derrida vê no pensamento heideggeriano do ser como evento, como Ereignis, uma certa expropriação, um impossível, no que escreve: “[...] o pensamento de Ereignis, em Heidegger, se voltaria não só para a apropriação do próprio (eigen), mas rumo a uma expropriação que o próprio Heidegger nomeia (Enteignis)." ${ }^{10}$ Reunindo o pensamento de Heidegger do evento ao inapropriável e à possibilidade: “Suportar o acontecimento, aquilo que, no sofrimento ou na provação, imediatamente se abre para e resiste à experiência, é, parece-me, uma certa inapropriabilidade do que surge ou acontece (de ce qui arrrive).”. Este seria, no entendimento de Raffoul, o percurso de Derrida ao pensamento da impossibilidade, a maneira como formula seu pensamento do impossível a partir do pensamento de Heidegger do Ereignis, do acontecimento.

\footnotetext{
7 DERRIDA, 2012, p.240.

8 Idem, ibidem, p.241.

9 RAFFOUL, 2007 , p.76.

10 HABERMAS; DERRIDA, 2004, p.100.
} 
Contudo, sendo não só isso que chega, de repente e sem aviso, o acontecimento também é aquilo que não se compreende, o deparar-se com a própria incompreensão. Derrida reconhece que todo acontecimento demanda um movimento de apropriação (compreensão, reconhecimento, identificação, descrição, determinação, interpretação com base em um horizonte de antecipação, conhecimento, denominação e assim por diante) que é inelutável, mas também - para que tal ocorrido seja entendido como verdadeiro acontecimento - é preciso que tal apropriação falhe, se mostre insuficiente.

E, sobre a dúvida se o acontecimento realmente chega, acompanhemos o que diz Derrida sobre o assunto: “Isso não quer dizer que isso não chega, que não o há; isso quer dizer que não posso dizê-lo em um modo teórico, que não posso nem o pré-dizer.”11 O que leva a pensar que o dizer permanece impotente frente à imprevisibilidade do acontecimento, no entanto, argumenta que essa impotência nunca é total. Relembra que tinha dito que o dizer do acontecimento supunha uma neutralização, uma generalização pela repetição que o dizer dá lugar:

Eu dizia agora mesmo que o dizer do acontecimento supunha uma forma de inevitável neutralização do acontecimento pela iterabilidade, que o dizer traz sempre em si a possibilidade de redizer: pode-se compreender uma palavra unicamente porque ela pode ser repetida; desde que eu fale, me sirvo de palavras repetíveis e a unicidade se desestabiliza nessa iterabilidade. Da mesma forma, o acontecimento não pode aparecer como tal, quando ele aparece, senão estando já em sua própria unicidade, repetível. É essa ideia, muito difícil de pensar, da unicidade enquanto sendo imediatamente iterável, da singularidade enquanto sendo imediatamente, como diria Lévinas, engajada na substituição. A substituição não é simplesmente o realojamento de um único substituível: a substituição substitui o insubstituível. Que existia imediatamente, desde a primeira manhã do dizer ou o primeiro surgimento do acontecimento, iterabilidade e retorno na unicidade absoluta, na singularidade absoluta, isso que faz a vinda do que chega - ou a vinda do acontecimento inaugural - não possa ser acolhida senão como retorno, reaparecência, aparição espectral. Que a impossibilidade do dom continue a assombrar o dom. Esse assombro é a estrutura espectral dessa experiência do acontecimento, ele é absolutamente essencial ${ }^{12}$. 
Apesar de extensa, esta citação nos apresenta uma consideração valiosa, a saber: o acontecimento já implica a iterabilidade que, embora represente uma inevitável forma de neutralização, é a estrutura invariável pela qual chega até nós; recebemos o acontecimento na medida em que podemos inseri-lo na linguagem, já como reaparecência do impossível que não deixa de assombrar isso que chegou. Ademais, essa iterabilidade é o próprio movimento de apropriação que vem logo em seguida. Vê-se então que, algo sempre é dito e repetido sobre o acontecimento, e que, por vezes, se é compelido a dizer.

Este foi o caso de Derrida, a respeito do que o título deste trabalho se refere como "o acontecimento"; o acontecimento, tamanha sua espetacularidade, e, malgrado o que foi mencionado em suas linhas sobre a hospitalidade, frustra a estrutura vertical da surpresa que vem do alto. Vinda inesperada do que já estava lá, de homens que haviam recebido treinamento no próprio Estados Unidos, e regressam, com força, para além de toda capacidade de acolhimento de duas torres, contra duas torres, dois aviões. Não só isso, mas sem dúvida, a imagem mais marcante da série de atentados que atingiram os Estados Unidos, no que até hoje só conseguimos nomear como 11 de setembro.

Pouco mais de um mês após o ocorrido, numa entrevista concedida à Giovanna Borradori, Derrida chama atenção para como uma data nomeia um acontecimento sem precedentes (unprecedented), algo que aconteceu pela primeira vez e última na história $^{13}$. Uma data para um fato que não temos conceito, de alguma coisa que permanece indescritível, do qual nossa linguagem permanece impotente, não avançando além do nome. Derrida frisa que não sabemos do que falamos quando dizemos 11 de setembro e, contudo, não cessamos de repetir essa data, na tentativa de apaziguar o trauma. Nessa impossibilidade de nomear adequadamente e pensar a questão, que não parece ser da violência e do grande número de mortos, não nos convencemos do que realmente tudo aquilo se tratou.

Tem-se a impressão que um major event aconteceu, imprimiu-se em nossos olhos, no entanto, Derrida chama atenção que, apesar dos horrores e a repreensão necessária, muito da comoção se deve por força da mídia, de modo que é difícil distinguir o que

13 HABERMAS; DERRIDA, 2004, p.95. 
aconteceu, de sua impressão e consequente interpretação. Percebe-se nesta entrevista a relutância do autor em ceder ao apelo histérico que, poucos dias do ocorrido, se era convocado a responder. E, somente após muita relutância, pontuando que não se tratava de um evento tão imprevisível, concorda em entende-lo em termos de acontecimento: "Afinal, toda vez que alguma coisa acontece, mesmo na mais banal experiência do cotidiano, existe em relação a isso algo de acontecimento e de singular imprevisibilidade: cada instante marca um acontecimento, e também tudo o que é “outro", e cada nascimento e cada morte, até a mais suave e mais "natural'.” ${ }^{14}$. Isso porque, embora não imprevisível de todo, muitos foram tomados de surpresa.

Numa tentativa de levantar as fontes do 11 de setembro, questiona se somos ou não aliados dos Estados Unidos, se aprovamos ou não sua política. Argumenta que o próprio 11 de setembro é um efeito do "fim da guerra fria", da época que os Estados Unidos proporcionavam treinamento e armas para o Afeganistão e os inimigos da União Soviética, que vieram se tornar inimigos seus. Chama atenção, que desde o fim deste período, o que se chama de ordem mundial e sua estabilidade, veio depender da solidez e confiabilidade do poder americano, de modo que, desestabilizar essa superpotência que desempenha o “papel” de guardiã da ordem vigente, é por sob ameaça o mundo inteiro, incluindo os inimigos declarados dos Estados Unidos.

Derrida busca mostrar que o que propõe não é nada de abstrato ou mera especulação teórica, analisando três eventos: “Guerra Fria”, “O fim da guerra fria” e “equilíbrio do terror" a partir da lógica do autoimune, ou seja, um processo auto-imunitário, que consiste no estranho comportamento pelo qual um ser vivo, de maneira quase suicida, trabalha "por si mesmo" para destruir a própria proteção, imunizar-se contra sua "própria" imunidade ${ }^{15}$. Derrida analisa o atentado como um golpe sofrido pelos Estados Unidos, um golpe em seu próprio território que vem como de dentro, imigrantes que receberam treinamento americano em solo americano, e que incorporam dois suicídios: o das próprias vidas, mas também o suicido daqueles que os acolheram, armaram e treinaram, e que de certo modo trabalharam para a própria morte. Tratou-se também de um ataque simbólico que atingiu lugares muito significativos do país, o centro econômico, World Trade Center, e centro militar, o Pentágono. Contudo, se-

14 HABERMAS; DERRIDA, 2004, p.101.

15 Idem, ibidem, p.104. 
gundo Derrida, o que caracteriza o acontecimento como traumático, não é somente a marca que deixa na memória, as imagens do horror, pois o que aterroriza é justamente a ferida aberta pelo terror que se toma do futuro, que se torna sombrio, imprevisível, e que talvez reserve algo de ainda pior.

Entretanto, tal ameaça já se anunciava desde o chamado "fim da guerra fira”, pois desde então, surgiram incontáveis redes terroristas armadas que se voltaram contra os Estados Unidos, dissolvendo a antiga polarização entre esta potência e a União Soviética. Derrida comenta que essa tentativa de dar por terminada essa etapa, negar ou atenuar os efeitos do traumatismo não passam de movimentos auto-imunitários que produzem, inventam e alimentam a própria monstruosidade que querem superar. O que nunca se deixará esquecer é o efeito perverso dessas ações auto-imunes, pois a repressão, tanto no sentido psicanalítico quanto político, acaba produzindo ainda mais aquilo que se tentava conter. Sobre esse círculo vicioso da repressão, Derrida alega que as estratégias de defesa, da "guerra ao terror" colaboram, a longo prazo, para impulsionar reinvestidas do que querem combater; os sucessivos ataques sempre provocarão mais mortes, do que se pode chamar de revoltas, mais ou menos legítimas, de um contraterrorismo ${ }^{16}$.

Em nome da clareza de exposição, se fez esta tripartição das fontes do terrorismo auto-imunitário, enquanto que, na verdade, estas três fontes do terror se autocondicionam. Não obstante, Derrida problematiza o emprego do termo "terrorismo", advertindo que devemos desconfiar da linguagem vigente que permanece, na maioria das vezes, a serviço da retórica midiática e política. Questiona como podemos diferenciar terror de medo, ansiedade e pânico. Do medo que conceituado de uma tradição de Hobbes a Schimitt e Benjamin, como condição de autoridade estatal. Seria toda experiencia de terror decorrente de um terrorismo? Pois, enquanto a história da palavra terrorismo deriva, em grande parte, de uma referência ao reinado do Terror durante a Revolução Francesa (um terror conduzido em nome do Estado que pressupunha o monopólio legal da violência), os crimes de terror são caracterizados contra a vida humana, violação de leis nacionais e internacionais, aterrorizando a população para influenciar a política de um país, com a alegação de ser uma retaliação a um terrorismo anterior.

16 HABERMAS; DERRIDA, 2004, p.109. 
Terrorismo então, parece ser um termo elástico, intercambiável, sempre transferido ao outro que se quer acusar. Tais atos confundem também as distinções entre nacional e internacional, como no caso da guerra franco-argelina (1954-1962) que demorou muito tempo para ser classificada como tal. De modo que se pode perguntar, como se distingue uma intervenção para manter a paz, do terrorismo e da guerra civil ou militar, no que comenta Derrida: “O poder dominante é aquele que consegue impor e assim legitimar, na verdade até legalizar (pois se trata sempre de uma questão de lei), em um palco nacional ou mundial, a terminologia e a interpretação que mais lhe convém em uma determinada situação.” ${ }^{17}$; nos lembra também que, foi assim que os Estados Unidos estipularam um consenso intergorvenamental na América do Sul para caracterizar oficialmente como terrorismo, qualquer resistência política contra os poderes estabelecidos, de modo que, uma coalisão armada pudesse combater o que assim foi chamado, delegando responsabilidade aos governos sul-americanos e, evitando uma intervenção estrangeira.

Desse modo, delineia-se o que podemos chamar de terrorismo de Estado, práticas das grandes potências que justificam intervenções militares ao se declararem alvo do que alegam ser “terrorismo”. E, uma vez que: “Atos “terroristas” tentam produzir efeitos psíquicos (conscientes ou inconscientes) e reações simbólicas ou sintomáticas que poderiam provocar inúmeros desvios, na verdade um número incalculável deles”18. As mídias são usadas como ferramentas para incutir emoções em seus telespectadores, causando reações, muitas vezes não proporcionais as perdas sofridas.

Consequentemente, não devemos nos perguntar quem é mais terrorista nesse combate, uma vez que a cobertura midiática do 11 de setembro serviu aos interesses específicos de cada um doa lados. Pois, enquanto os aliados ao grupo terrorista se felicitavam pelo ataque, os Estados Unidos não cessaram de tomar as imagens do terror, de ter sido alvo de tantos ataques e palco de tantas mortes como marca, prova de uma agressão que deveria ser revidada. A grande potência mundial assistiu à destruição de dois de seus maiores pináculos, ícones da civilização capitalista, como bem colocou Mondzain: “[...] o primeiro espetáculo histórico da morte da imagem na

17 Ibidem, p.114.

18 HABERMAS; DERRIDA, 2004, p.117. 
imagem da morte." ${ }^{19}$. No entanto, Derrida não vê nada de novo na relação terrorismo e mídia, pois um terrorismo opera se propagando dentro de um espaço público de imagens e rumores, buscando aterrorizar a população civil. De modo que é possível observar historicamente, o papel da propaganda em campanhas de bombardeio desde a Primeira Guerra Mundial.

A estratégia dos terroristas se mantém a mesma: derrubar, mas não assumir, desestabilizar a ordem corrente, mas também seus próprios aliados. Derrida entende isso como uma consequência necessária do mesmo processo auto-imunitário que, nos mais diversos tipos de guerras, cedo ou tarde, torna-se preciso confrontar não só o alvo principal, mas os aliados de combate. Esta é uma das razões pela qual não se deve considerar todo o islã ou o chamado "mundo árabe" como um todo homogêneo, pois há sempre diferenças, divergências. Posto isso, Derrida considera que devemos ajudar o que é chamado islã e o que é chamado "árabe”, que fogem dessa figura pérfida caracterizada pela mídia ocidental, ajudar quem de dentro luta contra as correntes dogmáticas e violentas, seja através de uma proposta política ou de uma interpretação do Corão ${ }^{20}$.

Quanto as “estratégias” (ideologias, armas e práticas) dos terroristas, uma das coisas que Derrida mais reprova não é tanto a crueldade e o desrespeito pela vida humana, mas a não abertura para nenhum futuro. Reprova o uso da tecnologia para implementar uma interpretação dogmática do Corão, o desrespeito pelo correlato ocidental de política e democracia, assim como a lei internacional, de modo que, se fosse preciso escolher - numa hipotética situação binária -, escolheria, apesar das reservas que mantém, o mundo ocidental e o espaço que deixa para a perfectibilidade em nome da "política", da democracia, da lei internacional, e das instituições internacionais assim por diante.

Já, quando perguntado sobre o papel da religião nesses conflitos, Derrida comenta que estamos falando de uma estranha "guerra" sem guerra, pois esta, em geral, assume a forma aparente de um confronto entre dois grupos de religiões opostas ${ }^{21}$. De um lado a grande potência “democrática” ao estilo europeu, em princípio laica, mas com

19 MOZIN, 2009, p.6.

20 HABERMAS; DERRIDA, op. cit., p.122.

21 HABERMAS; DERRIDA, 2004, p.127. 
uma forte referência bíblica, cristã. Do outro lado, a potência inimiga, identificada como fundamentalista islâmica. Duas teologias políticas, ambas estranhamente derivadas da mesma origem comum, do que chamaria de revelação "abraâmica”, de modo que se pode considerar metonimicamente esta oposição, a partir do confronto entre Israel e o Estado virtual da Palestina. Dado esse cenário, Derrida gostaria de esperar que venha da Europa, ou de certa tradição moderna, decorrente da desconstrução que ainda está encontrando seu caminho, a emergência de um outro discurso em relação ao presente embate teológico-político, do qual o 11 de setembro teria sido um dos efeitos dessa não resolução.

Quanto ao papel dianteiro da Europa na resolução desse conflito, diz esperar, mas não ver fatos que garantam qualquer certeza. De modo que se existem responsabilidades a serem assumidas, decisões a serem tomadas elas pertencem a um tempo de risco e a um ato de fé, além do conhecimento. Não se trata de decidir a partir do que já se sabe que deve ser feito, o que significaria apenas desdobrar um programa previsível, sem responsabilidade ou acontecimento. A escolha da Europa talvez se deva pela oposição que Derrida tem, não exatamente, contra os Estados Unidos, e sim em relação certa hegemonia americana, um modo de pensar, de agir que se difunde, domina e marginaliza o que considera estranho. Derrida deposita sua fé numa Europa forte, unificada, que possa fazer frente a tal hegemonia, proferir uma outra voz, de modo a poder modificar as premissas fundamentais da situação corrente.

Essa discussão sobre o sobre uma Europa forte, e a fé depositada nas instituições internacionais leva a uma interessante digressão sobre a democracia, a partir da pergunta de Borradori, se não haveria o risco de propor um Estado-modelo, um metaestado e uma metalei. Quanto a isto, Derrida responde, reconhecendo a complexidade da questão e, tendo como referências Kant e Arednt, que não se trata de um metaestado, mas de uma nova figura, a surgir, como último recurso da soberania, aliado não só a uma lei, mas também à justiça. Entendamos justiça aqui como a própria desconstrução, aquilo que chega, de modo que, ser aliado à justiça significa estar aberto a isso que vem, e não buscar estancar os devires das coisas, pessoas e estados.

É o que pretende Derrida na expressão “democracia por vir” (la démocratie à venir), não a ideia de uma futura democracia que se tornará "presente"; pois entende que a democracia nunca existirá no presente, ela se inscreve como promessa no que se apre- 
senta como impossível ${ }^{22}$. Existe o impossível e este permanece como tal por causa da aporia do demos, que é simultaneamente a singularidade incalculável de qualquer um, antes de qualquer "sujeito", “ser humano", anterior a todo “povo” ou "Estado", e também a generalidade de um cálculo racional, que engloba na universalidade da igualdade perante todos os cidadãos, da lei, e do laço social de estar junto. E, no entanto, esse impossível que existe permanece inapagável, pois trata-se de apontar para um outro regime do "possível-impossível”. Derrida tenta pensar a partir de outros caminhos questões pelas quais discute a ideia de acontecimento (doação, perdão, hospitalidade), sem se ater ao que a tradição considera por “possibilidade”, "poder” e "impossibilidade". Além disso, como arremate desse pensamento sobre os regimes políticos, não propõe pensar a democracia como um "regime político", já que nela se encontra a possibilidade de contestação, de aperfeiçoar-se indefinidamente. Talvez o problema seja com o nome "regime", uma vez que o que entende por democracia é algo que jamais se viu, jamais se apresentou de maneira estanque, mas aberta à perfectibilidade, se anunciando na penumbra.

No que diz respeito à globalização, Derrida diz preferir usar o termo francês mondialisation - um modo de preservar a ideia de mundo em oposição a globo ou cosmo - e considera que esta, a globalização, não ocorre em todos os espaços e nem para o benefício de todos, de modo que as disparidades nunca foram tão grandes, sendo não mais que um simulacro para disfarçar o crescente acúmulo de riquezas nas mãos de poucos. Já, relacionando tal tema à questão da tolerância, considera que este esteja relacionado ao que se chama "retorno do religioso", uma maneira de abordar a violência posta em questão. A religião usada para acusar bin Laden, também se encontra ao lado de Bush. A palavra tolerância é, antes de mais nada, marcada por uma guerra religiosa entre cristãos e não cristãos. A tolerância é uma virtude cristã, uma virtude católica. O cristão deve tolerar o não cristão, e deixá-lo existir. Nessa lógica, a paz seria a coabitação tolerante. Contudo, as declarações oficiais de tolerância sempre obedecem a uma estratégia, a um discurso de raízes religiosas, frequentemente usadas pelos que detém o poder, sempre como uma concessão condescendente.

Desse modo, a tolerância é um limite da hospitalidade, ou mesmo uma hospitalidade condicional. A hospitalidade pura, incondicional, é o estar aberto para o hospede 
não esperado, nem convidado. Derrida reconhece que a hospitalidade incondicional é praticamente impossível de se viver, assim como conferi-la estatuto legal e político - é a chegada inesperada, o próprio acontecimento ${ }^{23}$. No entanto, sem a ideia dessa hospitalidade pura e incondicional, da hospitalidade em si, não teríamos conceito algum de hospitalidade em geral, e sequer seríamos capazes de determinar qualquer regra para hospitalidade condicional, prevista em lei. Em seu entender, a ideia de hospitalidade pura é também o que permite a ideia do outro e sua alteridade, do visitante inesperado. Tal hospitalidade não é nem política nem jurídica, mas a condição anterior a esses dois campos.

Ao finalizar a entrevista, Borradori direciona as perguntas para a questão do cosmopolitismo como saída para pensar o problema da hospitalidade, de receber quem não se espera, e muitas vezes não se quer, como o caso dos refugiados. Derrida, diz a ideia de cosmopolitismo é uma ideia muito antiga, remontando a São Paulo, mas que Kant foi o último grande expoente. No tratado Paz perpétua, o filósofo defende que deveríamos desistir da ideia de uma república mundial (Weltrepublik), mas não de uma lei cosmopolítica, de modo que a ideia de uma cidadania mundial seria uma condição que nos aproximaria da paz perpétua. Contudo, é preciso adequar o espírito desta tradição aos nosso tempos e questões. Derrida pontua que o que chama de democracia por vir, iria além dos limites do cosmopolitismo, de uma cidadania mundial. Acredita que se deve fazer tudo para estender o privilégio de cidadania ao mundo, já que grande número de homens e mulheres ainda não o possui.

Perguntado se essa desconstrução do conceito de cosmopolitismo implica uma desconstrução do Estado, responde que o cosmopolitismo pressupõe alguma forma de soberania estatal, algo como um estado mundial e, para que essa desconstrução seja eficaz, ela não deve se opor ao conceito de Estado. No entanto, isso não deve obstruir uma desconstrução da forma do Estado, que um dia deve deixar de ser o correlato do político ${ }^{24}$.

Sobre a questão dos direitos humanos, considera que é cada vez mais em nome dos direitos humanos e de sua universalidade que a autoridade soberana do Estado é pos-

23 HABERMAS; DERRIDA, 2004, p.139.

24 HABERMAS; DERRIDA, 2004, p.141. 
ta em questão, que tribunais internacionais de justiça são formados e que chefes de Estado e líderes militares são julgados depois de terem sido retirados das instituições judiciais de seus próprios países. O conceito de crime contra a humanidade ou crimes de guerras estão acima da jurisdição nacional, no que convoca: "É preciso (il faut) mais do que nunca ficar do lado dos direitos humanos. São necessários (il faut) direitos humanos.”25. Tais direitos são precisos, pois há sempre uma carência, uma insuficiência; os direitos humanos jamais são o bastante. Não devemos esquecer também que não são naturais, possuem uma história recente, complexa e inacabada. $\mathrm{E}$ em nome de uma perfectibilidade, devemos sempre revisitar e questionar conceitos como humanidade do homem, o homem ou humano, o conceito de direito, crime contra a humanidade, para que tais direitos possam ajudar os que deles precisam.

\section{REFERÊNCIAS BIBLIOGRÁFICAS}

DERRIDA, Jacques. Uma certa possibilidade impossível de dizer o acontecimento. Tradução de: Piero Eyben. Revista Cerrados, Brasília, v. 21, n. 33, p.229-251, 2012.

. Penseur de l'événement. L’humanité. Saint Denis, s/p, 28 de janeiro de 2004

HABERMAS, Jürgen; DERRIDA, Jacques. Filosofia em tempo de terror: diálogos com Jürgen Habermas e Jacques Derrida / Giovanna Borradori; tradução de Roberto Muggiati. Rio de Janeiro: Editora Jorge Zahar, 2004.

MONDZAIN, Marie-José. A imagem pode matar? Tradução de: Susana Mouzinho. Lisboa: Editora Nova Veja, 2009 .

MORIN, Edgar. Le retour de l'événement. In: Communications, 18, 1972. L'événement. pp. 6-20.

RAFFOUL, François. Derrida et l'éthique de l'im-possible. In: Revue de métaphysique et de morale. $2007 / 1\left(\mathrm{n}^{\mathrm{o}} 53\right), \mathrm{p} .73-88$.

25 Idem ibidem. p,142. 